\title{
Rheotaxis Response Based on Sexual Dimorphism in the Green Swordtail Fish, Xiphophorus hellerii
}

\author{
Muhammad Irsyad A. Ghafari and Vita Fitrianti \\ Universitas Mataram, Mataram, West Nusa Tenggara, Indonesia \\ Corresponding author: vitafitrianti99@gmail.com
}

\begin{abstract}
Morphological distinctions between males and females of a species are referred to by sexual dimorphism. It may result from various selection pressures affecting either sex or both and may occur in any dioecious species, including Green Swordtail fish, which are sexually reproductive. This study examined the different rheotaxis responses of Xiphophorus hellerii based on different sexes and morphological features. We analyzed ten adult males, ten gravid females, and ten non-gravid females of Xiphophorus helleri collected down the river and transferred into the column. We counted the number of the individual that performed positive rheotaxis $(+)$, negative rheotaxis $(-)$, and indifference response $(0)$. The result showed different rheotaxis responses shown by male, non-gravid female, and gravid female $X$. hellerii. The highest percentage of positive rheotaxis response (movement against the current) was shown by non-gravid female $X$. hellerii, reaching up to $89 \%$. Morphological differences between male, non-gravid female, and gravid female $X$. hellerii appear to affect the orientation and ability of $X$. hellerii in giving response against current and certainly has an impact on their survival in nature.
\end{abstract}

Keywords: Rheotaxis, Sexual dimorphism, Green Swordtail, Xiphophorus hellerii

\section{Introduction}

Rheotaxis response is a form of behavioral adaptation response to the movement of water flow in the environment. Rheotaxis response is caused by the sensory system that is lined the lateral line along the fish body (Ge et al., 2018; Oteiza et al., 2017). A small functional unit comprises smooth ciliated epithelia called neuromast, located along the lateral line and acts as a hydrodynamic sensor (Liu et al., 2016). The neuromast is a susceptible epithelium, and it will move according to the direction of flowing water that passes along the lateral line (Herzog et al., 2015). The movement stimulates the sensory nerves to send signals to the central nerve and responds in the form of coordinated body movement and orientation (Hecker et al., 2020).

Rheotaxis response plays a vital role in the survival of a fish in the wild. The ability to respond to the current is closely related to the morphological aspect and influences habitat selection (Mogdans, 2019). Rheotaxis response could be in the form of positive rheotaxis or negative rheotaxis. Positive rheotaxis is a movement orientation against the oncoming current, while negative rheotaxis is a movement correspond to the direction of water current. Rheotaxis becomes the main driving force in determining most river fish migration(Bak-Coleman et al., 2015). Australian fish species, silver perch (Bidyanus bidyanus), Murray cod (Maccullochella peelii), and eel-tailed catfish (Tandanus bunch), 
their ability to move and swim orientation were influenced by body shape, depth, and their response to the water flow velocity (Shiau et al., 2020).

Cavefish (Astyanax mexicanus) utilize high sensitivity of neuromast to efficiently detect prey vibrating at $30-40 \mathrm{~Hz}$ in water (Fernandeset al., 2018). In the species, Melanotaenia australis, the abundance of superficial neuromasts that function to facilitate rheotaxis (body orientation into currents) in each body region varies greatly and varies between populations and individuals (Spiller et al., 2017). Several studies have shown that populations of guppies (Poecilia reticulata) above barrier waterfalls in the Aripo and Turure rivers in Trinidad show positive rheotaxis (Blondel et al., 2020).

Zebrafish (Danio rerio) that live in freshwater systems with low visibility showed strong positive rheotaxis and respond to geomagnetic fields (Cresci et al., 2017). Similarly, zebrafish larvae (Danio rerio) respond to rheotaxis using a flow velocity gradient as a navigation guide (Oteiza et al., 2017). Olive et al. (2016) reported the rheotaxis behavior of freely-swimming larval zebrafish in a radial flow assay showed clear position holding, both angularly and radially, when visual or hydromechanical cues could be exploited. Based on Bak-Coleman \& Coombs (2014), passive fish is relying mostly on rheotaxis response.

A preliminary study regarding the rheotaxis orientation related to different sexes and body shape is useful to understand the pattern and barrier of sedentary fish local migration and their survival mechanism. This study was used green swordtail (Xiphophorus hellerii) as the observation subject, a species of sedentary freshwater fish that is well known to have sexual dimorphism. A longer caudal fin indicates sexual dimorphism in swordtail fish in males and it is thought to influence their rheotaxis response in nature. The purpose of this study was to analyze the rheotaxis response in fish based on different sexes and morphological features.

\section{Material and Method}

\subsection{Overview}

The experiment was done in March 2018, in a small river located in Cakranegara, Mataram City $\left(8^{\circ} 34^{\prime} 00^{\prime \prime S}, 116^{\circ} 08^{\prime} 08^{\prime \prime E}\right)$. The result of our preliminary observation (that was done several weeks before collecting data) shows the high percentage of wild Xiphophorus hellerii population in the river, making it easier to find an experimental subject on site.

\subsection{Sample Collection and Experimental animals}

The collection of Xiphophorus hellerii was carried out using a fishing net, walking along the river for $30 \mathrm{~m}$ away. The mesh diameter of the fishing net is approximately 4.760 $\mathrm{mm}$ (mesh size type 4). The fish that has been caught then transferred into a transparent tank with a ruler on the bottom of the tank to facilitate the estimation of body length and the separation of male, non-gravid female, and gravid female $X$. hellerii and other non- 
targeted species of fish (as shown in Figure 1). The morphological difference between male, non-gravid female, and gravid female $X$. hellerii is shown in Figure 1 . Only adult $X$. hellerii with body length approximately $7-8 \mathrm{~cm}$ were taken for the experiment. The estimation of fish body length refers to the Standard Length Measurement (SLM) method, as explained by (Tang \& Chang, 2016). The identification for male and female X. hellerii refers to (Grzimek et al., 2004).

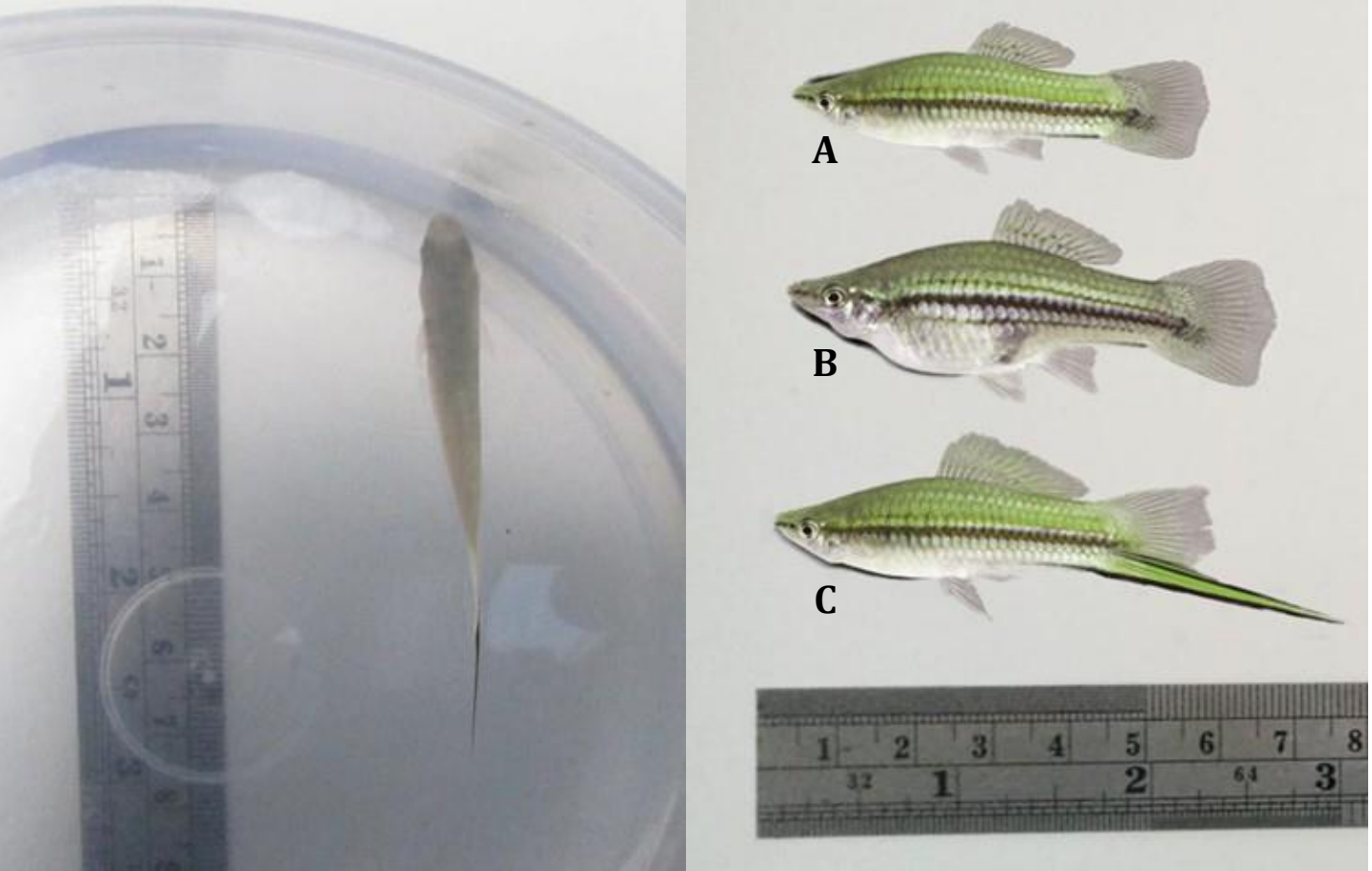

Figure 1. (Left) Estimation of fish body length; (Right) Morphological difference between A) non-gravid female, B) gravid female, and C) male $X$. hellerii.

\subsection{Measuring Water Flow Velocity}

The experiment was done in-situ using a rheotaxis box. The Control column is filled with water and then set the box cap to close the entry point so that the water can not flow into the control column. The rheotaxis boxes were laid down until $2 / 3$ of their height were drowned into the clear water for easy observation.

The measurement of water flow velocity was carried out before the experiment began using the Lagrarian method (Tang \& Chang, 2016; Zhang et al., 2017). A cork ball was released at the water's surface. The cork ball's velocity was calculated, assuming the cork ball's velocity when moving is the same as the water current's velocity. The measurement inside the box was carried out with three times repetitions. In contrast, the measurement outside the box was carried out at the same point where the Xiphophorus hellerii was taken along the river. 


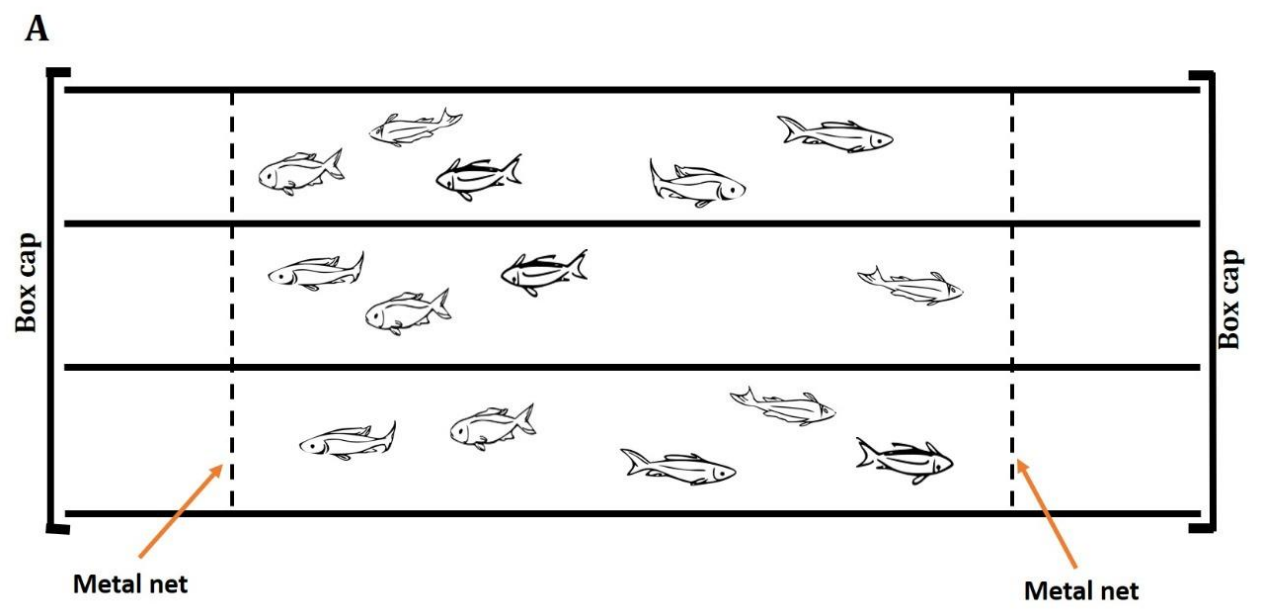

B

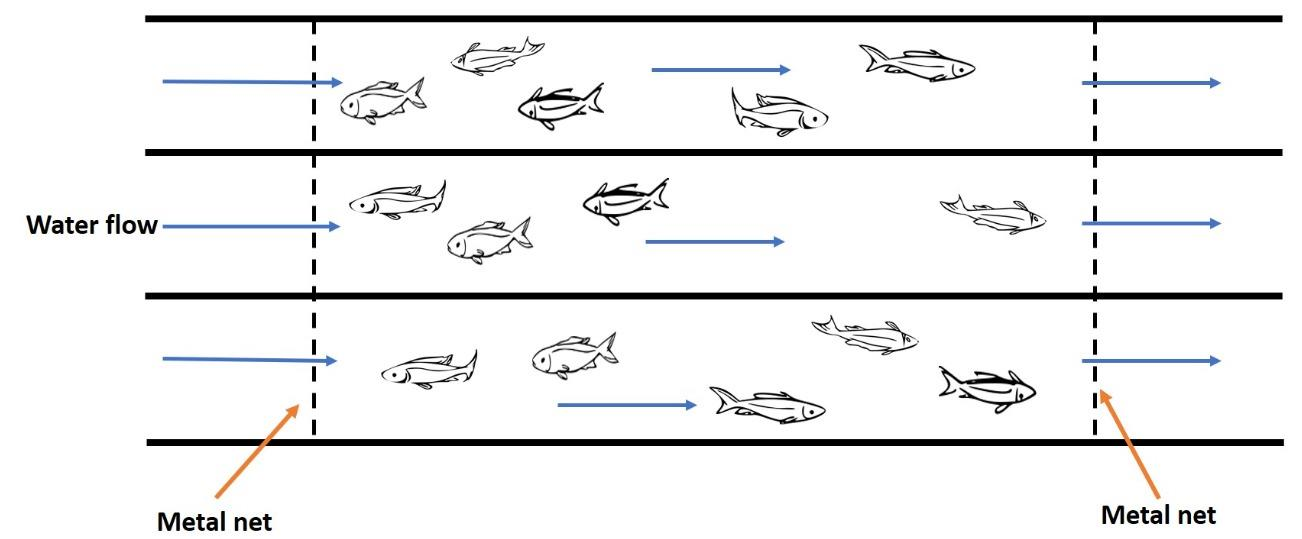

Figure 2. Illustration of rheotaxis box. A) Rheotaxis box for control column (with no flowing water) and B) Rheotaxis box for experiment column.

A total of 10 individuals for each male, non-gravid female, and gravid female of Xiphophorus hellerii were transferred into the experiment column and control column. Acclimatization was performed for 15 minutes, followed by counting the number of individual of $X$. hellerii that showed a positive rheotaxis $(+)$, negative rheotaxis $(-)$, and indifference response (0) during a time interval of 2 minutes with ten times observations for both experiment and control column. The experiment was conducted with three times replications for valid results.

\section{Results and Discussion}

\subsection{Results}

The water flow velocity data was taken inside and outside the rheotaxis box, including river bodies and river banks' flow velocity data. The average water flow velocity at each measurement position is presented in Table 1. The average water flow velocity inside and outside the rheotaxis box. 
Table 1. The average water flow velocity inside and outside the rheotaxis box

\begin{tabular}{llc}
\hline \multicolumn{2}{l}{ The Measurement Positions } & The Average of Water Flow Velocity \\
\hline \multirow{2}{*}{ Inside the box } & River body & $0.731 \mathrm{~m} / \mathrm{s}$ \\
& River bank & $0.672 \mathrm{~m} / \mathrm{s}$ \\
\multirow{2}{*}{ Outside the box } & Control column & $0.003 \mathrm{~m} / \mathrm{s}$ \\
& Experimen column & $0.439 \mathrm{~m} / \mathrm{s}$ \\
\hline
\end{tabular}

The result shows the response of Xiphophorus hellerii to the flowing water in the form of a different response, including positive rheotaxis (against the current), negative rheotaxis (in the direction of the current), and indifference (random orientation, including perpendicular movement to the direction of the current). The result showed different responses between male, non-gravid female, and gravid female $X$. hellerii inside the experiment column, as indicated in Table 2. Percentage of rheotaxis response showed by Xiphophorus hellerii in both experiment and control column. In the experiment column, it is known that the non-gravid female $X$. hellerii has the highest percentage of positive rheotaxis response, reach up to $89 \%$, and gravid female showed the lowest percentage of positive rheotaxis response, only reached $34.5 \%$. The percentage of rheotaxis responses showed by $X$. hellerii in the control column has a normal pattern, where all the fish move randomly without being affected by current.

Table 2. Percentage of rheotaxis response showed by Xiphophorus hellerii in both experiment and control column

\begin{tabular}{lcccccc}
\hline & \multicolumn{5}{c}{ Percentage of Rheotaxis Response (\%) } \\
\cline { 2 - 7 } Fish Type & \multicolumn{3}{c}{ Experiment Column } & \multicolumn{3}{c}{ Control Column* } \\
\cline { 2 - 7 } & - & $\mathbf{0}$ & $\mathbf{+}$ & - & $\mathbf{0}$ & + \\
\hline Male (o') & 8.5 & 11.5 & 80 & 33.33 & 34 & 32.67 \\
Non-gravid Female (n-G\%) & 1.5 & 9.5 & 89 & 32.33 & 33.80 & 33.87 \\
Gravid Female (Go) & 41.5 & 24 & 34.5 & 32.75 & 33 & 33.25 \\
\hline
\end{tabular}

*Note: The direction of water flow outside the box becomes 'standard direction of water flow' in the control column due to zero current inside the box.

\subsection{Discussion}

Both male, non-gravid female, and gravid female of Xiphphorus hellerii have very different morphological features and produce different hormonal factors. The advantage of morphological features seems to contribute to the high percentage of rheotaxis response in non-gravid female $X$. hellerii. Non-gravid females of $X$. hellerii have more slender and shorter bodies than their male and gravid female counterparts. Morphological adaptation of stream fish is mostly on the locomotion part, consisting of a variation on the abdominal shape, caudal regions, and fins (Shuai et al., 2018; Hanif et al., 2019). The slender body of stream fish is crucial to enhance the ability to swim against the stream (Mu et al., 2019; Wagle et al., 2015). Dunn et al. (2020) reported population morphological variations of Galaxias brevipinnis, Galaxias gollumoides, and Galaxias 
Vulgaris in lotic habitats have a slender body to their lentic-habitats counterparts. Adaptations of body shape to survive in natural habitat are also found in fish from semiarid Australia. The population from fast-flowing has more excellent swimming resistance against water flow than the other populations from slow-flowing (Kelley et al., 2017).

The changes in morphological features in gravid Xiphophorus hellerii could contribute to their low percentage of rheotaxis response. During the gravid phase, lipid storage in the body will accumulate, so the fish body would be less slender and decrease the fish's ability to move against the current one (Haas et al., 2010; Fleuren et al., 2019). Although the lipid storage is useful for pelagic fish, such as the great white shark (Carcharodon carcharias) in terms of buoyancy setting as well as a source of energy during long migration (Raye et al., 2013), it seems that the same mechanisms do not occur in sedentary freshwater fish. Quicazan-Rubio et al. (2019) reported that the guppy fish (family: Poeciliidae) had increased body volume up to $43 \%$, as well, as their frontal body area has expanded up to $69 \%$ during the gravid period, causing the fish movement in flowing water becomes much heavier due to the greater thrust of the flowing water against the enlarged body. Besides, the abdomen and muscles' flexibility will be decreased during the gravid period, which results in the decreasing of the maximum speed of the fish when swimming (Quicazan-Rubio et al., 2019). Yan et al. (2015) and Dhurmeea et al. (2018) reported that the lipid in sedentary gravid fish would be entirely stored in gonadal and other visceral organs, and the concentration of TLS (total lipid storage) in muscles will decrease. Consequently, due to lack of TLS in muscles, muscles' ability to create movement will be decreased, primarily to support the body that has increased in mass.

On the other hand, hormonal factors may correspond to the morphological difference in how gravid fish respond to the flowing water. The hormonal factors influence gravid Xiphophorus hellerii in responding to the current stimuli (Weidner et al., 2020). Estrogen appears to have responsibility for the decline of fish's responsive behavior against current and triggers the hiding behavior of gravid fish (Liley, 1972; Stacey, 1981). Several types of estrogen, such as $17 \beta$-estradiol and phytoestrogens, are known to influence decreasing the dominance status of male fish in their group, as well as making the fish less aggressive in the wild (Clotfelter \& Rodriguez, 2006; Filby et al., 2012; Pinto et al., 2014). The increasing production of estrogen during the gravid period influences the behavioral change, which gives the fish an ecological advantage in reducing the risk of predation in nature (by promoting the hiding behavior and decreasing the rate of movement) and as an effort to save energy during pregnancy.

Hormonal factors also seem to influence rheotaxis response in non-gravid female Xiphophorus hellerii, which is very high compared to male and gravid $X$. hellerii in the experiment column. According to Deal \& Volkoff (2020), the fish movement in current water will more active with the increasing level of thyroxine and GH (growth hormone). GH stimulates increasing energy production by enhancing the physiological and behavioral respects (Deal \& Volkoff, 2020). GH is also known to influence fish behavior to 
become more active and aggressive(Hallerman et al., 2007). Another type of hormone, such as PRL (prolactin), also affects the increasing rate of the fish movement against the current (Whittington \& Wilson, 2013), even though that the PRL holds primary function in fish osmoregulation (Breves, 2020). PRL is a hormone found naturally in both mature male and female fish, but the female is known to have a higher concentration of PRL compared to male fish (Whittington \& Wilson, 2013). In other words, the production of GH, thyroxine, and PRL support more active movement (Hallerman et al., 2007). The combination of morphological and hormonal advantages makes a perfect combination for the non-gravid female fish to survive in fast-flowing water (figure 3).

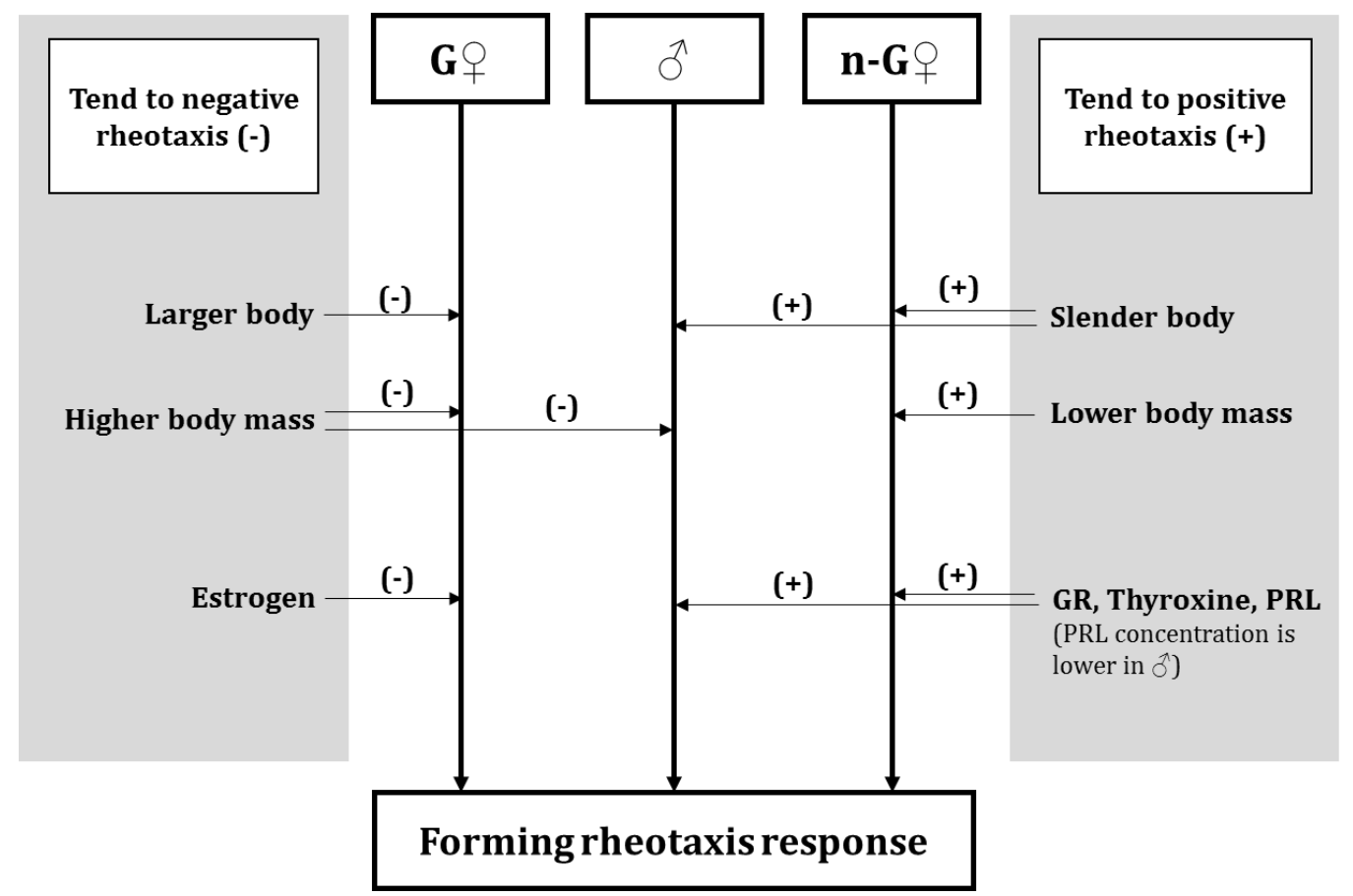

Figure 3. The factors influence rheotaxis responses. The responses could be different between sexes with different morphological and physiological conditions. This scheme's indifferent movement may be influenced by other factors, such as light (phototaxis) and dissolved $\mathrm{O}_{2}$ level in the water (DO).

The difference of morphological features can be proposed due to the percentage difference of rheotaxis response between male and non-gravid female Xiphophorus hellerii. Based on Basolo \& Alcaraz (2003), the elongated caudal fin in male Xiphophorus sp. gives an evolutionary loss by causing a decrease in male fish ability to resist the current, even though such an ornamental tail is handy in attracting the female during courtship ritual. Moreover, the elongated caudal fin in adult male Xiphophorus sp. causes the increasing body mass and leads to higher $\mathrm{O}_{2}$ consumption, which is indicated by higher energy expenditure for moving (Basolo \& Alcaraz, 2003). Similarly, wider and larger ornamental caudal fin in male guppies led to the fish's decreasing ability to swim against the current due to the increasing hydrodynamic obstacles experienced by the fish (Hockley et al., 2014; Karino et al., 2006). In contrast, a sedentary-benthic fish, such as Pterygoplichthys spp., has a flattened belly and low movement rate, resulting in low 
energy cost to spend and less current friction to face (Blake, 2006; Moroni et al., 2015). In some fish species, smaller fins fit better in fast-flowing water habitat because reducing drag produces more propulsion efficiency while swimming in a current (Svozil et al., 2020).

\section{Conclusion}

The slender and shorter body much influences a high percentage of positive rheotaxis shown by the non-gravid female of X. hellerii as a morphological advantage. The males $X$. hellerii have an elongated caudal fin, and it becomes an obstacle in resisting the current, but this problem may only be found in adult males who are ready to mate. On the other hand, the movement of gravid female $X$. hellerii tend to follow the current direction. Nevertheless, the passive response of gravid females provides the ecological benefits for their survival in nature. It also assumes that different hormonal factor due to sexual dimorphism influences the rheotaxis response, but we need more field evidence to support this assumption.

\section{References}

Bak-Coleman, J., \& Coombs, S. (2014). Sedentary behaviour as a factor in determining lateral line contributions to rheotaxis. The Journal of Experimental Biology, 217(13), 2338 LP - 2347. https://doi.org/10.1242/jeb.102574

Bak-Coleman, J., Smith, D., \& Coombs, S. (2015). Going with, then against the flow: Evidence against the optomotor hypothesis of fish rheotaxis. Animal Behaviour, 107(2015), 7-17. https://doi.org/10.1016/j.anbehav.2015.06.007

Basolo, A. L., \& Alcaraz, G. (2003). The turn of the sword : length increases male swimming costs in swordtails. In Proceeding of The Royal Society B (pp. 1631-1636). https://doi.org/10.1098/rspb.2003.2388

Blake, R. W. (2006). Biomechanics of rheotaxis in six teleost genera. Canadian Journal of Zoology, 84(8), 1173-1186. https://doi.org/10.1139/Z06-105

Blondel, L., Klemet-N'guessan, S., Scott, M. E., \& Hendry, A. P. (2020). Asymmetric isolation and the evolution of behaviours influencing dispersal: Rheotaxis of guppies above waterfalls. Genes, 11(2), 180. https://doi.org/10.3390/genes11020180

Breves, J. P. (2020). Hormonal regulation of aquaporins in fishes. In G. Litwack (Ed.), Vitamins and Hormones (1st ed., Vol. 112, pp. 265-287). Elsevier Inc. https://doi.org/10.1016/bs.vh.2019.10.002

Clotfelter, E. D., \& Rodriguez, A. C. (2006). Behavioural changes in fish exposed to phytoestrogens. Environmental Pollution, 144(3), 833-839. https://doi.org/10.1016/j.envpol.2006.02.007 
Cresci, A., Rosa, R. De, Putman, N. F., \& Agnisola, C. (2017). Comparative Biochemistry and Physiology, Part A Earth-strength magnetic field affects the rheotactic threshold of zebrafish swimming in shoals. Comparative Biochemistry and Physiology, Part A, 204(2017), 169-176. https://doi.org/10.1016/j.cbpa.2016.11.019

Deal, C. K., \& Volkoff, H. (2020). The Role of the Thyroid Axis in Fish. Frontiers in Endocrinology, 11(November), 1-25. https://doi.org/10.3389/fendo.2020.596585

Dhurmeea, Z., Pethybridge, H., Appadoo, C., \& Bodin, N. (2018). Lipid and fatty acid dynamics in mature female albacore tuna (Thunnus alalunga) in the western Indian Ocean. PLoS ONE, 13(4), 1-20. https://doi.org/10.1371/journal.pone.0194558

Dunn, N. R., O'Brien, L. K., Burridge, C. P., \& Closs, G. P. (2020). Morphological convergence and divergence in galaxias fishes in lentic and lotic habitats. Diversity, 12(5), 13-16. https://doi.org/10.3390/D12050183

Fernandes, V. F. L., Macaspac, C., Lu, L., \& Yoshizawa, M. (2018). Evolution of the developmental plasticity and a coupling between left mechanosensory neuromasts and adaptive foraging behavior. Developmental Biology, 441(2), 262-271. https://doi.org/10.1016/j.ydbio.2018.05.012

Filby, A. L., Paull, G. C., Searle, F., Ortiz-Zarragoitia, M., \& Tyler, C. R. (2012). Environmental estrogen-induced alterations of male aggression and dominance hierarchies in fish: A mechanistic analysis. Environmental Science and Technology, 46(6), 3472-3479. https://doi.org/10.1021/es204023d

Fleuren, M., Leeuwen, J. L. Van, \& Pollux, B. J. A. (2019). Superfetation reduces the negative effects of pregnancy on the fast-start escape performance in live-bearing fish. In Proceeding of The Royal Society B of The Royal Society B (p. 286). The Royal Society.

Ge, A., Wang, X., Ge, M., Hu, L., Feng, X., Du, W., \& Liu, B. (2018). Profile analysis of C. elegans rheotaxis behavior using a microfluidic device. Lab on Chip, 19(3), 475-483. https://doi.org/10.1039/c8lc01087k

Grzimek, B., Schlager, N., McDade, M. C., Olendorf, D., Zoo, A., \& Association, A. (2004). Grzimek's Animal Life Encyclopedia , 2nd Edition Overview Alternate Formats. Gale.

Haas, T. C., Blum, M. J., \& Heins, D. C. (2010). Morphological responses of a stream fish to water impoundment. Biology Letters Evolutionary Biology, 6(May), 803-806. https://doi.org/10.1098/rsbl.2010.0401

Hallerman, E. M., McLean, E., \& Fleming, I. A. (2007). Effects of growth hormone transgenes on the behavior and welfare of aquacultured fishes: A review identifying research needs. Applied Animal Behaviour Science, 104(3-4), 265-294. https://doi.org/10.1016/j.applanim.2006.09.008 
Hanif, M. A., Siddik, M. A. B., Islam, M. A., Chaklader, M. R., \& Nahar, A. (2019). Multivariate morphometric variability in sardine, Amblygaster clupeoides (Bleeker, 1849), from the Bay of Bengal coast, Bangladesh. The Journal of Basic and Applied Zoology, 80(1). https://doi.org/10.1186/s41936-019-0110-6

Hecker, A., Anger, P., Braaker, P. N., Schulze, W., \& Schuster, S. (2020). High-resolution mapping of injury-site dependent functional recovery in a single axon in zebrafish. Communications Biology, 3(1). https://doi.org/10.1038/s42003-020-1034-x

Herzog, H., Steltenkamp, S., Klein, A., Tätzner, S., Schulze, E., \& Bleckmann, H. (2015). Micro-machined flow sensors mimicking lateral line canal neuromasts. Micromachines, 6(8), 1189-1212. https://doi.org/10.3390/mi6081189

Hockley, F. A., Wilson, C. A. M. E., Brew, A., \& Cable, J. (2014). Fish responses to flow velocity and turbulence in relation to size, sex and parasite load. Journal of the Royal Society Interface, 11(91), 1-11. https://doi.org/10.1098/rsif.2013.0814

Karino, A., Karino, K., Orita, K., \& Sato, A. (2006). Long Tails Affect Swimming Performance and Habitat Choice in the Male Guppy Long Tails Affect Swimming Performance and Habitat Choice in the Male Guppy. Zoological Science, 23(3), 255-260. https://doi.org/10.2108/zsj.23.255

Kelley, J. L., Davies, P. M., Collin, S. P., \& Grierson, P. F. (2017). Morphological plasticity in a native freshwater fish from semiarid Australia in response to variable water flows. Ecology and Evolution, 7(16), 6595-6605. https://doi.org/10.1002/ece3.3167

Liley, N. R. (1972). The effects of estrogens and other steroids on the sexual behavior of the female guppy, Poecilia reticulata. General and Comparative Endocrinology, 3(SUPPL.), 542-552. https://doi.org/10.1016/0016-6480(72)90185-2

Liu, G., Wang, A., Wang, X., \& Liu, P. (2016). A Review of Artificial Lateral Line in Sensor Fabrication and Bionic Applications for Robot Fish. Applied Bionics and Biomechanics, 2016, 15. https://doi.org/10.1155/2016/4732703

Mogdans, J. (2019). Sensory ecology of the fish lateral-line system: Morphological and physiological adaptations for the perception of hydrodynamic stimuli. Journal of Fish Biology, 95(1), 53-72. https://doi.org/10.1111/jfb.13966

Moroni, F. bio T., Ortega, A. nio C., Moroni, R. B., Mayag, B., Jesus, R. Rio S. de, \& Lessi, E. (2015). Limitations in decision context for selection of amazonian armoured catfish acari-bod (Pterygoplichthys pardalis) as candidate species for aquaculture. International Journal of Fisheries and Aquaculture, 7(8), 142-150. https://doi.org/10.5897/ijfa15.0480

$\mathrm{Mu}, \mathrm{X}$. , Cao, P., Gong, L., Baiyin, B., \& Li, X. (2019). A classification method for fish swimming behaviors under incremental water velocity for fishway hydraulic design. Water (Switzerland), 11(10), 1-16. https://doi.org/10.3390/w11102131 
Olive, R., Wolf, S., Dubreuil, A., Bormuth, V., Debrégeas, G., \& Candelier, R. (2016). Rheotaxis of larval zebrafish: Behavioral study of a multi-sensory process. Frontiers in Systems Neuroscience, 10(FEB), 1-9. https://doi.org/10.3389/fnsys.2016.00014

Oteiza, P., Odstrcil, I., Lauder, G., Portugues, R., \& Engert, F. (2017). A novel Mechanism for Mechanosensory-Based Rheotaxis in Larval Zebrafish. Nature, 547(27 July 2017), 112. https://doi.org/10.1038/nature23014

Pinto, P. I. S., Estêvão, M. D., \& Power, D. M. (2014). Effects of estrogens and estrogenic disrupting compounds on mineralized fish tissues. Marine Drugs, 12(8), 4474-4494. https://doi.org/10.3390/md12084474

Quicazan-Rubio, E. M., Van Leeuwen, J. L., Van Manen, K., Fleuren, M., Pollux, B. J. A., \& Stamhuis, E. J. (2019). Coasting in live-bearing fish: The drag penalty of being pregnant. Journal of the Royal Society Interface, 16(151), 20180714. https://doi.org/10.1098/rsif.2018.0714

Raye, G. Del, Jorgensen, S. J., Krumhansl, K., Ezcurra, J. M., \& Block, B. A. (2013). Traveling light: white sharks ( Carcharodon carcharias ) rely on body lipid stores to power ocean-basin scale migration. In Proceeding of The Royal Society B (p. 280). https://doi.org/10.1098/rspb.2013.0836

Shiau, J., Watson, J. R., Cramp, R. L., Gordos, M. A., \& Franklin, C. E. (2020). Interactions between water depth, velocity and body size on fish swimming performance: Implications for culvert hydrodynamics. Ecological Engineering, 156(December 2019), 105987. https://doi.org/10.1016/j.ecoleng.2020.105987

Shuai, F., Yu, S., Lek, S., \& Li, X. (2018). Habitat effects on intra-species variation in functional morphology: Evidence from freshwater fish. Ecology and Evolution, 8(22), 10902-10913. https://doi.org/10.1002/ece3.4555

Spiller, L., Grierson, P. F., Davies, P. M., Hemmi, J., Collin, S. P., \& Kelley, J. L. (2017). Functional diversity of the lateral line system among populations of a native Australian freshwater fish. Journal of Experimental Biology, 220(12), 2265-2276. https://doi.org/10.1242/jeb.151530

Stacey, N. E. (1981). Hormonal Regulation of Female Reproductive Behavior in Fish 1. American Zoologist, 316(December 1979), 305-316. https://doi.org/10.1093/icb/21.1.305

Svozil, D. P., Baumgartner, L. J., Fulton, C. J., Kopf, R. K., \& Watts, R. J. (2020). Morphological predictors of swimming speed performance in river and reservoir populations of Australian smelt Retropinna semoni. Journal of Fish Biology, 97(6), 1-12. https://doi.org/10.1111/jfb.14494 
Tang, W., \& Chang, S. (2016). A Semi-Lagrangian method for the weather options of meanreverting Brownian motion with jump-diffusion. Computers and Mathematics with Applications, 71(5), 1045-1058. https://doi.org/10.1016/j.camwa.2015.12.040

Wagle, S. K., Pradhan, N., \& Shrestha, M. K. (2015). Morphological Divergence of Snow Trout (Schizothorax Richardsonii, Gray 1932) from Rivers of Nepal with Insights from a Morphometric Analysis. International Journal of Applied Sciences and Biotechnology, 3(3), 464-473. https://doi.org/10.3126/ijasbt.v3i3.13123

Weidner, J., Jensen, C. H., Giske, J., Eliassen, S., \& Jørgensen, C. (2020). Hormones as adaptive control systems in juvenile fish. Biology Open, 9(2), 1-16. https://doi.org/10.1242/bio.046144

Whittington, C. M., \& Wilson, A. B. (2013). The role of prolactin in fish reproduction. General and Comparative Endocrinology, 191(15 September 2013), 123-136. https://doi.org/10.1016/j.ygcen.2013.05.027

Yan, J., Liao, K., Wang, T., Mai, K., Xu, W., \& Ai, Q. (2015). Dietary lipid levels influence lipid deposition in the liver of large yellow croaker (Larimichthys crocea) by regulating lipoprotein receptors, fatty acid uptake, and triacylglycerol synthesis and catabolism at the transcriptional level. PLoS ONE, 10(6), 1-16. https://doi.org/10.1371/journal.pone.0129937

Zhang, X., Chen, Z., \& Liu, Y. (2017). A Continuum-Based Particle Method for Extreme Loading Cases. The Material Point Method (pp. 1-9). London, United Kingdom: Academic Press. https://doi.org/10.1016/b978-0-12-407716-4.00001-6 